UDC 343.211:373.72

LBC 67.408.121.2

\title{
DIFFERENTIATION OF CRIMINAL RESPONSIBILITY FOR FRAUD IN LENDING: OPINIONS OF THE ENFORCERS ${ }^{1}$
}

\author{
Sona M. Mkrtchyan \\ Volgograd State University, Volgograd, Russian Federation
}

Introduction: the article contains the results of the study of the practitioners' views regarding the validity of the differentiation of criminal responsibility for credit fraud undertaken in 2012. Objective: to study the practitioners' opinions regarding the advisability of introducing special provisions on fraud in lending (Article 159) in the Criminal Code, as well as to determine the most preferable directions of developing the system of measures to struggle against this crime. Methods: the study is comprehensive. The specifically sociological methods and research techniques are widely used. Results: it is noted that the idea of a significant part of the practitioners to make special components of fraud in lending under Article 159 of the Criminal Code found no support. It was also found that, in the opinion of a significant number of the law enforcement officers, the introduction of Article 159 in the Criminal Code did not contribute to improving the practice of qualifying fraud in the credit sphere. It is found that the vast majority of those asked practitioners do not agree with the lowering of the legal limits of punishment stipulated in the sanctions of Part 1 of Article 159 of the Criminal Code. It is proposed to consider the possibility of supplementing Part 2 of Article 159 of the Criminal Code of the Russian Federation with the qualifying element "with the use of financial straits and other predicament of a citizen". Scope of application: the results of the study can be used in law-enforcement, legislative and scientific activities. Conclusions: it is concluded about the unreasonableness of the differentiation of criminal responsibility for credit fraud, and the need of deleting Article 159 from the Criminal Code in order to prevent the excessive casuistry of criminal law.

Key words: differentiation of criminal responsibility, fraud, lending, fraud in lending, sociological study.

УДК 343.211:373.72

ББК 67.408.121.2

\section{ДИФФЕРЕНЦИАЦИЯ УГОЛОВНОЙ ОТВЕТСТВЕННОСТИ ЗА МОШЕННИЧЕСТВО В СФЕРЕ КРЕДИТОВАНИЯ: МНЕНИЕ ПРАВОПРИМЕНИТЕЛЕЙ ${ }^{1}$}

\author{
Сона Мартиросовна Мкртчян \\ Волгоградский государственный университет, г. Волгоград, Российская Федерация
}

\begin{abstract}
Введение: статья содержит результаты исследования мнения практических работников относительно обоснованности осуществленной в 2012 году дифференциации уголовной ответственности за кредитное мошенничество. Цель: изучить мнение практических работников относительно целесообразности введения в УК РФ специальной нормы о мошенничестве в сфере кредитования (ст. 1591), а также определить наиболее предпочтительные направления развития системы мер борьбы с указанным преступлением. Методы: исследование носит комплексный характер. Широко применяется конкретно-социологический метод и прине нашла поддержки. Обнаружено также, что, по мнению значительного числа правоприменителей, введение ст. $159^{1}$ в УК РФ не способствовало совершенствованию практики квалификации мошеннических действий в кредитной сфере. Установлено, что подавляющее большинство опрошенных практических работни() ков не согласны с понижением законодательных пределов назначения наказания, установленных в санкции
\end{abstract}


ч. 1 ст. $159^{1}$ УК РФ. Предлагается рассмотреть возможность дополнения ч. 2 ст. 159 УК РФ квалифицирующим признаком «с использованием тяжелого материального и иного затруднительного положения гражданина». Область применения: результаты исследования могут быть использованы в правоприменительной, законодательной и научной деятельности. Выводы: сделаны выводы о необоснованности произведенной дифференциации уголовной ответственности за кредитное мошенничество, а также о необходимости исключения ст. $159^{1}$ из УК РФ в целях недопущения чрезмерной казуистичности уголовного закона.

Ключевые слова: дифференциация уголовной ответственности, мошенничество, кредитование, мошенничество в сфере кредитования, социологическое исследование.

\section{Введение}

Обоснованность конструирования ст. $159^{1}$ УК РФ резонно оценивать с позиции необходимости создания специальных норм, устанавливающих ответственность за те или иные варианты мошеннического поведения, при наличии статьи, обладающей высоким уровнем абстракции (ст. 159 УК РФ). В качестве причин возникновения специальных норм в науке справедливо называют необходимость в практических целях подчеркнуть преступность каких-то определенных действий, актуализировать борьбу с той или иной разновидностью деяний путем конкретизации признаков наказуемого поведения [1, с. 19-20]. Может показаться, что из этих соображений исходили и инициаторы дополнения Уголовного кодекса ст. $159^{1}-159^{6}$ [2]. Но действительно ли конструирование самостоятельной статьи о кредитном мошенничестве отвечало интересам правоприменителей? Поддерживают ли они произведенную законодателем дифференциацию уголовной ответственности за кредитное мошенничество?

\section{Необходимость конструирования специальной нормы о мошенничестве в сфере кредитования}

На первый взгляд, результаты проведенного нами социологического исследования позволяют утвердительно ответить на первый из указанных вопросов. Так, $62,2 \%$ респондентов (67 человек) отметили, что ст. 159 УК РФ не справлялась с предупреждением кредитного мошенничества и не учитывала современные мошеннические схемы в кредитной сфере. Указанное, однако, опровергается тем, что с квалификацией мошенничества под прикрытием кредитного договора у практических работников особых сложностей не возникало. В подобной ситуации уголовное дело возбуждалось по ст. 159 [3]. Не случайно в ходе опроса обнаружилось, что правоприменитель не столь уж убежден в том, что в появлении ст. $159^{1}$ имелась настоятельная необходимость. Во-первых, значительная часть опрошенных практических работников $(37,4 \%$, то есть 40 человек) указала, что предыдущая редакция УК РФ не нуждалась в изменении, она могла применяться к различным проявлениям мошенничества, в том числе в современных условиях. Во-вторых, на вопрос о том, с чем связано выделение мошенничества в сфере кредитования в качестве самостоятельного состава преступления, самым востребованным оказался ответ «с непродуманным решением законодателя» (42,2 \% опрошенных, или 46 человек).

Может показаться, будто данные проведенного нами опроса указывают на то, что появление ст. $159^{1}$ значительно облегчило процесс квалификации соответствующих преступных деяний. С указанным тезисом согласилось большинство респондентов (59,8 \% опрошенных, или 64 человека). Вместе с тем значительная часть практиков $(33,6 \%$, или 36 человек) выбрала абсолютно противоположный вариант ответа. При этом из всех респондентов в ответе на вопрос «Как Вы считаете, какой вариант модернизации уголовного законодательства в сфере борьбы с кредитным мошенничеством наиболее предпочтителен?» лишь 9 человек (8,4 \% опрошенных) не заявили о необходимости исключения ст. $159^{1}$ УК РФ или ее усовершенствования.

\section{Обоснованность дифференциации уголовной ответственности за мошеннические действия в кредитной сфере}

Только 19,6 \% опрошенных (21 человек) считают преступление, предусмотренное ст. $159^{1}$ УК РФ, менее общественно опасным, 
чем мошенничество, предусмотренное ст. 159. Причем четыре человека объяснили это тем, что причиняемый мошенничеством вред более ощутим для гражданина или юридического лица, чем для кредитной организации, которая к тому же обладает средствами защиты своего имущества. Указанный подход противоречит сложившейся судебной практике, так как по ст. $159^{1}$ УК РФ квалифицируются мошеннические действия в отношении не только банков, но и менее крупных финансовых организаций, которые не всегда обладают дополнительными средствами защиты или внушительными резервными фондами.

Неудивительно, что большинство респондентов (77,6 \%, или 83 человека) не признали мошенничество в сфере кредитования менее общественно опасным преступлением. При этом практические работники не отрицают целесообразности модернизации уголовно-правовых мер борьбы с кредитным мошенничеством. Значительная их часть $(30,8 \%$, или 33 человека) согласилась с необходимостью исключить ст. $159^{1}$ из УК РФ. Кроме того, еще пять человек $(4,7$ \%) предложили одновременно с этим сконструировать в УК РФ составы наиболее опасных видов хищения в сфере кредитования.

На возможность подобного развития уголовно-правовой политики в сфере борьбы с мошенничеством указывают результаты ответа на вопрос относительно дополнения ч. 2 ст. 159 УК РФ квалифицирующим признаком «с использованием тяжелого материального или иного затруднительного положения гражданина» («за» высказалось 18,7 \% респондентов, или 20 человек). Необходимость обсуждения такого дополнения уголовного закона назрела в связи с распространением действий лиц, использующих стесненное материальное положение или затруднительную ситуацию, в которую попал потерпевший, для навязывания путем обмана кредитных услуг или установления процентов, явно не соразмерных обычным условиям кредитования.

\section{Выводы}

Подводя итоги проведенного социологического исследования, отметим следующее. Значительная часть правоприменителей не поддерживает идею создания специальной нормы о кредитном мошенничестве (ст. $159^{1}$ УК РФ). Негативно оценивается также решение сконструировать более мягкую санкцию за преступление, предусмотренное ст. $159^{1}$, в сравнении с санкцией, предусмотренной ст. 159 УК РФ. В этой связи предлагается проведенную дифференциацию в зависимости от сферы совершения мошеннических действий признать необоснованной и исключить ст. $159^{1}$ из УК РФ в целях недопущения чрезмерной казуистичности уголовного закона.

\section{ПРИМЕЧАНИЕ}

${ }^{1}$ Исследование основано на результатах проведенного в мае 2017 г. опроса 107 практических работников.

\section{СПИСОК ЛИТЕРАТУРЫ}

1. Горелик, А. С. Конкуренция уголовно-правовых норм / А. С. Горелик. - Красноярск : Изд-во Красноярского государственного университета, 1998. -108 c.

2. Постановление Пленума Верховного Суда РФ «О внесении в Государственную Думу Федерального Собрания Российской Федерации проекта федерального закона "О внесении изменений в Уголовный кодекс Российской Федерации и иные законодательные акты Российской Федерации"» от 5 апр. 2012 г. № 6. - Электрон. текстовые дан. - Режим доступа: https://www.vsrf.ru/Show_pdf.php?Id=7871 (дата обращения: 26.05.2017). - Загл. с экрана.

3. Приговор Кировского районного суда г. Самары от 15 апр. 2011 г. по уголовному делу № 1-248/ 11. - Электрон. текстовые дан. - Режим доступа: https://rospravosudie.com/court-kirovskij-rajonnyjsud-g-samary-samarskaya-oblast-s/act-102510078/ (дата обращения: 01.06.2011). - Загл. с экрана.

\section{REFERENCES}

1. Gorelik A.S. Konkurentsiya ugolovnopravovykh norm [Collision of Criminal Legal Norms]. Krasnoyarsk, Izd-vo Krasnoyar. gos. un-ta, 1998. 108 p.

2. Postanovlenie Plenuma Verkhovnogo Suda RF "O vnesenii v Gosudarstvennuyu Duти Federalnogo Sobraniya Rossiyskoy Federatsii proekta federalnogo zakona "O vnesenii izmeneniy v Ugolovnyy kodeks Rossiyskoy Federatsii $i$ inye zakonodatelnye akty Rossiyskoy Federatsii”” ot 5 apr. 2012 g. № 6 [The 
Decree of Supreme Court of the Russian Federation "On Introducing into the State Duma of the Federal Assembly of the Russian Federation of Draft Federal Law 'On Amending the Criminal Code of the Russian Federation and Other Legal Acts of the Russian Federation" "of April 5, 2012 no. 6]. URL: https://www.vsrf.ru/ Show_pdf.php?Id=7871. (accessed May 26, 2017).
3. Prigovor Kirovskogo rayonnogo suda g. Samary ot 15 apr. 2011 g. po ugolovnomu delu № 1-248/11 [The Verdict of the Kirov District Court of Samara of April 15, 2011 on Case no. 1-248/11]. URL: https://rospravosudie.com/court-kirovskij-rajonnyjsud-g-samary-samarskaya-oblast-s/act-102510078/. (accessed June 1, 2017).

\section{Information about the Author}

Sona M. Mkrtchyan, Assistant Professor, Department of Criminal Law, Volgograd State University, Prosp. Universitetsky, 100, 400062 Volgograd, Russian Federation, s.mkrtchian1992@volsu.ru.

\section{Информация об авторе}

Сона Мартиросовна Мкртчян, ассистент кафедры уголовного права, Волгоградский государственный университет, просп. Университетский, 100, 400062 г. Волгоград, Российская Федерация, s.mkrtchian1992@volsu.ru. 